\section{ON A NEW SYNTHESIS OF TYROSINE.}

By P. W. LATHAM, M.D. CANTAB., F.R.C.P. LOND., DOWNING PROFESSOR OF MEDICINF, UNIVERSITY OF CAM BRIDGE, 1874-94; CONSULTING PHYSICLAN TO ADDENIBOOKF'S HOSPITAL, CAMIRIDGE.

IN THE LANCET of Dec. 16th, 1905, p. 1757, I described a new metbod for the synthesis of tyrosine from anhydrous prussic acid and $p$ oxy-benzaldehyde; a method not only interesting in itself but, as I suggested, affording an explanation of the mode of formation of tyrosine in the animal body-namely, by the combination of adenine with the above-mentioned aldehyde.

In the section on p. 1759, describing the mode of directly transforming $p$-oxy-benzoyl-amino-cinnamic acid into tyrosine, there is an important clerical error with regard to the amount of barium bydrate which was employed and which is there stated to be "about 6.0 grammes." The amount should be $2 \cdot 25$ grammes. On making a number of further experiments with fresh materials I found that if more than 2.25 grammes are employed little or no tyrosine is produced, as an excess of hydrogen is liberated and the reduction of the $p$-oxy-benzoyl. amino cinnamic acid is carried too far. This error, however, has been turned to good account and has led me to an improved and much more simple method. After making several experiments it occurred to me to dispense altogether with the barium hydrate and to try what action potassium cyanide alone would have upon the oxy-acid. The result was most satisfactory. Not only is the $p$ oxy-benzoyl-amino. cinnamic acid reduced by the cyanide to benzoyl tyrosine, but the latter is also simultaneously decomposed into tyrosine and benzoic acid, a result I had not anticipated. The following are the changes :-

$$
\begin{aligned}
2 \mathrm{KCN}+4 \mathrm{H}_{2} \mathrm{O}= & (\mathrm{H}, \mathrm{COO})_{2} \mathrm{H}_{2}+2 \mathrm{NH}_{3} \\
& \text { Potassium rormate. } \\
= & \mathrm{H}_{2}+(\mathrm{COO})_{2} \mathrm{~K}_{2}+2 \mathrm{NH}_{3} \\
& \text { Potassium oxalate. }
\end{aligned}
$$

and

$$
\begin{aligned}
& \text { OH. } \mathrm{C}_{6} \mathrm{H}_{1} \mathrm{CH}: \text { C.NH.CO } \mathrm{C}_{6} \mathrm{H}_{5} \\
& \text { ' } \mathrm{COH} \\
& p \text {-oxy-benzoyl-amino-cinnamic acid. } \\
& =\text { OH. } \mathrm{C}_{6} \mathrm{H}_{4} \cdot \mathrm{CH}_{2} \cdot \mathrm{CH} \cdot \mathrm{NH} \mathrm{CO} \cdot \mathrm{C}_{6} \mathrm{H}_{5} \\
& \mathrm{COOH}
\end{aligned}
$$

which acted upon by the ammonia and water is resolved into OH. $\mathrm{C}_{6} \mathrm{H}_{4} \cdot \mathrm{CH}_{2} \cdot \mathrm{CH}\left(\mathrm{NH}_{2}\right) \mathrm{COOH}$ and $\mathrm{C}_{6} \mathrm{H}_{5} . \mathrm{COONH}_{4}$ Tyrosine. Ammonium benzoate.

The process, therefore, is much simplified and the yield of tyrosine is greater than when the barium hydrate is used. The only drawback is that the amount of colouring matter is considerable and necessitates a large dilution of the contents of the combustion tube before decolourising with animal charcoal, as well as two or three recrystallisations, each involving marked loss in the product.

I have made a number of experiments with different proportions of $\mathrm{KCN}$ at various temperatures and with varying results. The following, however, are the details of the experiment which yielded the best result, the proportion of the oxy-acid to the $\mathrm{KCN}$ employed being one molecule of the former and three molecules (instead of two) of the latter. $7 \cdot 1$ grammes of $p$-oxy-benzoyl-amino-cinnamic acid togetber with five grammes of $\mathrm{KCN}$ (98 per cent.) were placed in a combustion tube and to this mixture 48 cubic centimetres of hot water were added. The tube was then sealed (the contents occupying about one-half its capacity) and heated for three hours to a temperature gradually rising from $130^{\circ}$ to $170^{\circ} \mathrm{C}$. The temperature was then raised and maintained for four and a half hours between $175^{\circ}$ and $182^{\circ} \mathrm{C}$. On opening the tube there was a free escape of ammonia. The contents of the tube were washed out with hot water and well diluted, so that the total amount measured 300 cubic centimetres. The dark solution was filtered and then placed in a water bath $\left(100^{\circ} \mathrm{C}\right.$.) with animal charcoal for half an hour, and again filtered and evaporated to dryness at $100^{\circ}$. The residue (still coloured) was then treated with small (juantities of oold water to dissolve out the potassium oxalate, \&c., and the solution aspirated, leaving the impure tyrosine behind. This was now dissolved in dilute aqueous ammonia, filtered, and then evaporated in the water bath to about 36 cubic centimetres when crystals of tyrosine began to form on the margin of the liquid. The solution whilst hot was poured into a watch glass and set aside for 12 hours, when the tyrosine was found to have crystallised out almost completely in the form of beautiful silky colourless sheaves of needles. The mother liquor was then separated by aspiration with a pipette. The yield of tyrosine in this experiment was 0.6 gramme, being 13.2 per cent. of the theoretical amount-that is, 4.54 grammes. Its melting point was found to be $237^{\circ} \mathrm{C}$ and Millon's and Piria's tests gave the usual reactions.

Mr. M. M. Pattison Muir, to whose valuable help and encouragement in this investigation I have been greatly indebted, kindly undertook to analyse some of the specimens for me. The following are the details of his analysis. On combustion, 0.1785 gramme yielded 0.3862 gramme $\mathrm{CO}$, and 0.1002 gramme $\mathrm{H}_{2} \mathrm{O}$. For the nitrogen determination 0.2055 gramme yielded 13.4 cubic centimetres of nitrogen at $20^{\circ} \mathrm{C}$. and 774 millimetres pressure.

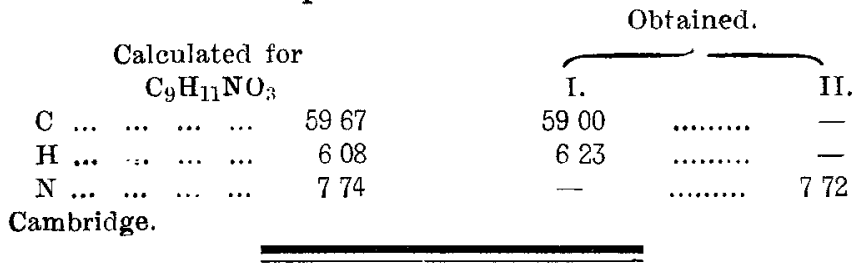

\section{A CASE OF EPILEPTIC IDIOCY ASSO- CIATED WITH TUBEROSE SCLEROSIS OF THE BRAIN.}

By MARGARET B. DOBSON, M.D. LoNd , PATHOLOGIST TO THE WEST RIDING ASYLUM, WAKEFIELD.

THE patient, a male epileptic idiot, was admitted into the West Riding Asylum, Wakefield, on Feb. 16th, 1901. He died on May 25th, 1906. aged ten years, from pneumonia, accelerated by exbaustion from epilepsy.

Family history. - The mother is of a nervous temperament and the father suffers from a "weak chest." A brother, aged seven years, suffers from epileptic fits and is extremely impulsive and emotional. Two maternal uncles died from convulsions at the age of two years and four months and one year and four months respectively. A paternal uncle was intemperate and died from pulmonary tuberculosis and three paternal aunts died from the same disease. A maternal great-uncle was addicted to alcoholic excess and is now in an asylum suffering from general paralysis of the insane. A maternal great-aunt was an inmate of the West Riding Asylum, Wakefield, in 1886-87, suffering from alcoholic pseudo-paralytic dementia.

Clinical history. - The patient was healthy and well formed at birth. Labour was normal, no forceps being used. He was the eldest of four living children. At the age of three or four weeks "twitching of the face and nodding of the head" was noticed. Convulsions resembling those of idiopathic epilepsy commenced one year after birth. The patient's mental condition on admission to the asylum was as follows. He was a low grade idiot and was unable to do anything for himself. He would grasp and pull to pitces or twist anything that was given to him. He made inarticulate noises and was quite incapable of answering the simplest questions. In his habits he was wet and dirty. As regards his physical condition he was below the average size, the frontal region of the skull was prominent, and his head was of the usual size. 'The palate was of the low, broad type. The teeth were good. The lobules of the ears were deficient. He suffered from the somewhat rare skin affection known as adenoma sebaceum. Little nodules were noticed on his face, occupying chiefly the cheeks and naso-labial folds; a few were noticed on the forehead. The nodules had a symmetrical distribution on the lower part of the face : their consistence was hard, their surfaces were smooth and dome-shaped, and the skin over them showed no blocked sebaceous duct. Vascular telangiectases around and between these nodules gave the patient a pink flusher look. The heart and lungs were normal. No sensory abnorm: symptoms were noticed during life. His gait was peculiar in that he had a tendency to walk on his toes and seemed incapable of walking in a straight line; he would rotate 
round an fixed object on the floor in a direction from right to left. He suffered from epileptic seizures of the grand mal and petit mal type. The convulsions were frequently pre ceded by a shrill cry and affected both sides of the body equally. The average number of fits were from two to six per diem.

Post-mortem examination - The skull was symmetrical. The calvarium was thicker than normal; the diploë was increased and somewhat congested. The inner surface was smooth and not adherent to the underlying dura mater. The dura mater presented no pathological change and the sub-dural tluid was not in excess. The pia-arachnoid was healthy looking except over the sclerosed areas of the brain, to be described below; it was here remarkably like tissu paper and stripped from the underlying cortex much more

\section{Fig. 1.}

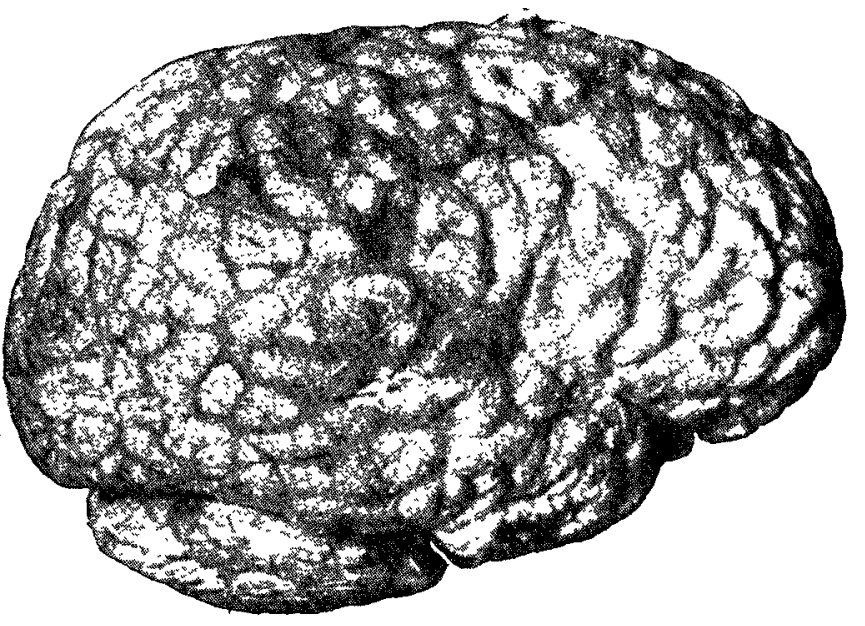

Right hemisphere covered with pia-arachnoid of a tissuepaper like appearance over the areas of sclerosis in frontal region.

FIG. 2.

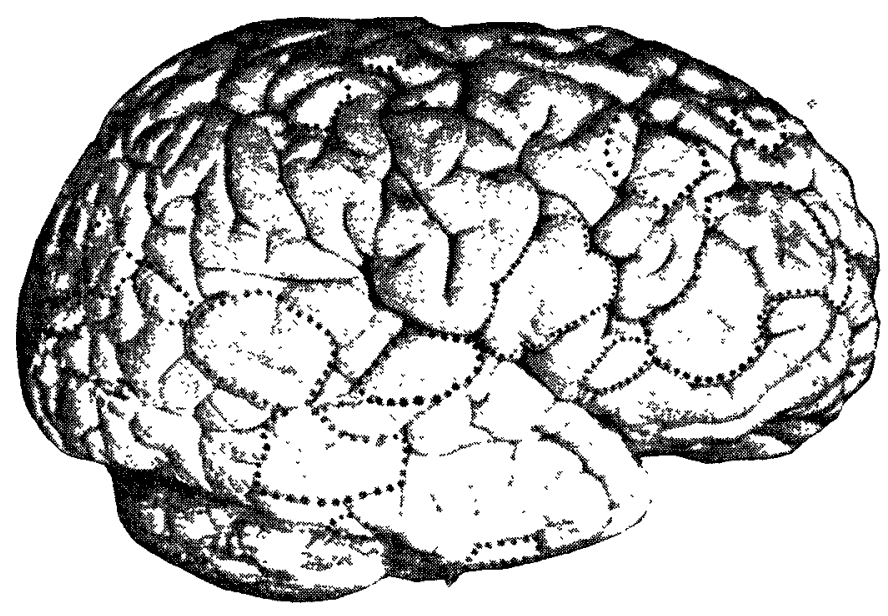

Right hemisphere. The dotted lines mark the boundaries of sclerosed areas of outer surface.

readily than elsewhere. Over the umbilications, however, it was firmly adherent. The brain weighed 1000 grammes; the right hemisphere, including the corresponding half of the cerebellum, pons, and medulla. weighed 500 grammes, and the left hemisphere weighed 495 grammes. The hemispheres were fairly symmetrical, the convolutions and sulci being well formed and complicated. On close examination of the cortex large, white, granular-looking, and exceedingly hard areas were found, occupying more especially the frontoparietal and temporo-sphenoidal lobes of both hemi-pheres. These sclerosed areas protruded slightly above the general surface of the brain and a few showed central umbilication. On section these areas showed considerable cortical hypertrophy ; they were white in colour, and the normal striations were almost absent. The cortex was badly defined and tended to pass gradually into the underlying medulla. The transition from normal to sclerosed cortex was sharp. The vessels of the medulla, more especially in the occipital regions, were surrounded by collars of gelatinons looking material. The lateral ventricles were not dilated. The choroid plexuses were healthy. Under the ependymal lining, which was smooth and glistening, hard, white, nodular growths were seen (varying in size from that of a pin's head to that of a small hazel nut) projecting into the ventricular cavity. These growths occurred in the groove between the caudate nucleus and the optic thalamus and appeared to run along the course of, and to be intimately connected with, the vein of the corpus striatum. Two very tiny growths appeared on the wall of the third ventricle; the fourth ventricle was healthy. No pathological change was noticed in the cerebellum, pons, or medulla. Red hepatisation of both lungs was present. No change of any interest was found in the other organs of the body.

Micrus'opical examination.-(1) The areas of solerosis.The sclerotic areas presented a firm, dense net-work of fibres quite devoid of cells. In other parts, where the sclerotio process was less advanced, the fibres were more closely interwoven. The matrix was mottled, ancl scattered singly and in

FIG. 3.

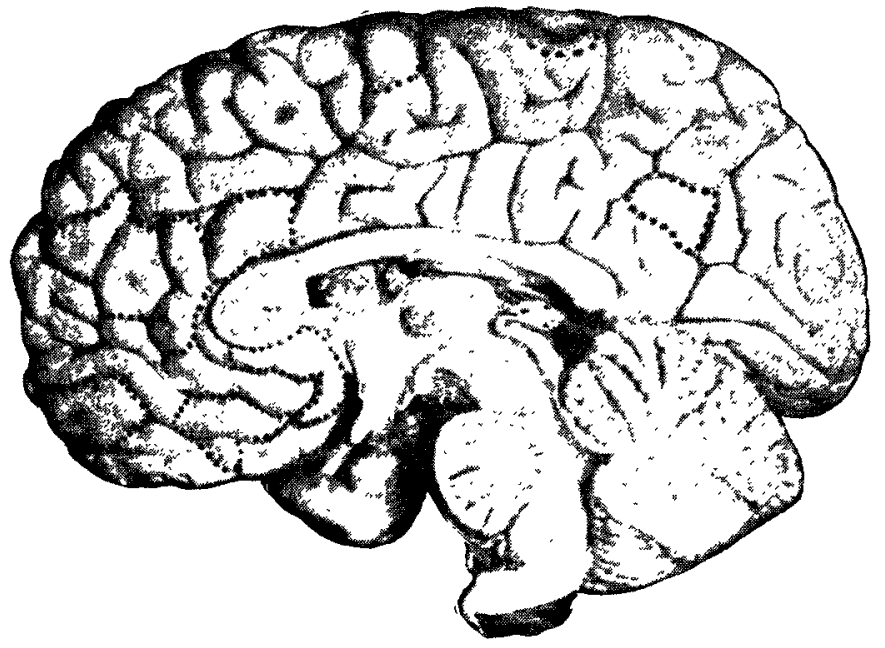

Right hemisphere. The dotted lines mark the boundaries of sclerosed areas of inner surface.

FIG. 4.

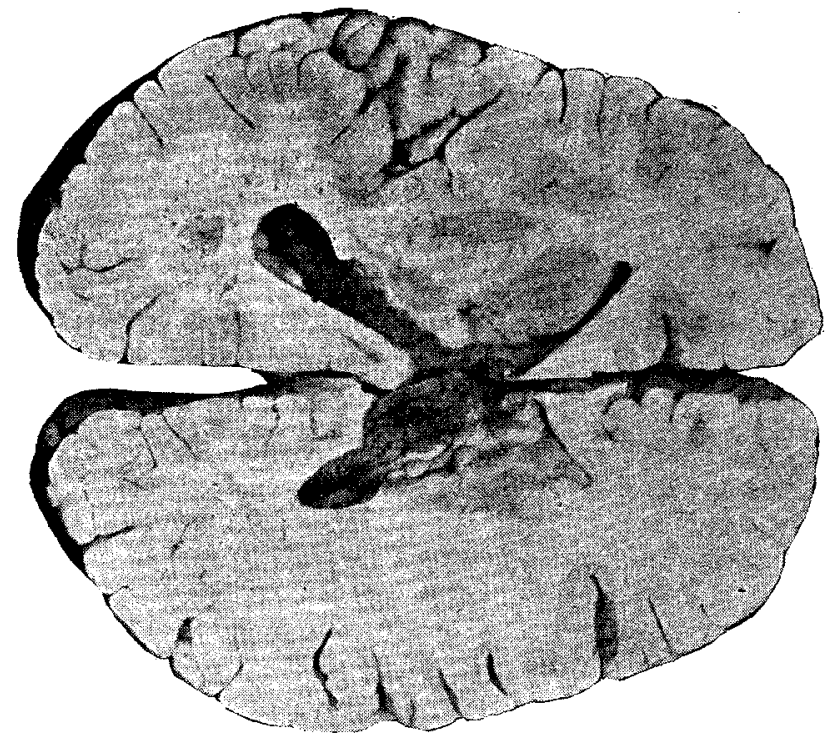

Section through lateral ventricles of brain showing subependymal tumours. Blood-vessels of medulla are surrounded by collars of mucoid material.

groups were very large, irregularly shaped "giant" cells, the protoplasm of which stained uniformly by the aniline blue-black fresh method of Bevan-Lewis and also by the Nissl method. In more normal parts of the section the pyramidal cells had undergone advanced degeneration; they had a battered look, the nuclei were displaced and chromato. lysis was well marked. The dendrites were few in number and the axis-cylinder was broken. Vacuolation was not present. The neuroglial cells were increased in size and number but not to any great extent. The blood-vessels were contained in dilated perivascular sheaths. Near the surface aggregations of hæmatoidin crystals were seen.

(2) Sub ependymal tumours. - The tumours were covered by a single layer of columnar-shaped epithelial cells. Beneath this healthy ependymal lining a firm, dense mesh-work of fibres, contrining numerous cells, was seen. The bloodvessels in this layer were fairly numerous and were contained 
in dilated perivascular canals. The main growth beneath this layer was composed of coarse connective tissue, the blood-vessels of which had thick diseased coats, the lumen being almost entirely obliterated in some instances. Around and apparently in close connexion with the vessels an extraordinary number of amyloid bodies with concentric markings were found. The margins of a few were c:enulated.

(3) Blood-vessels of the medulla.-The vessels were contained in round wide spaces. Surrounding the vessel wall and occupying this space were found cells having long, delicate intertwining branches. The appearance suggested myxomatous degeneration of the adventitial coat.

Wakefield.

\section{A CASE IN WHICH ACUTE APPENDICITIS AND A TWISTED OVARIAN PEDICLE EXISTED AT THE SAME TIME.}

\section{BY JOHN CAHILL, M.D. Durh , F.R.C.S. ENG.,}

\author{
AND
}

SiR WILLIAM H. BENNETT, K.C.V.O., F.R.C.S. ENG. CONSULTING SURGEON 'TO SH. GEORGl's HOSITTAL.

THE subject of this communication is a young woman who bad been under the observation of Dr. Cahill since her early childhood. Until the sudden onset of the illness about to be described she had never exhibited any symptom of any pelvic disorder, although she had always been of active habits and accustomed to dancing, bicycling, riding and other forms of exercise.

The patient, aged 17 years and apparently in good health, was seized with severe abdominal pain during the night of June 8th, 1905. When seen on the morning of the 9 th she was in great distress and had for some hours been vomiting at frequent intervals a considerable quantity of bile-stained mucus. The bowels had acted for the last time on the previous day. On examination the abdomen was moderately distended, the respiratory movements were very slightly limited, and some tenderness and resistance over the right iliac fossa were manifest but no dulness could be detected. The temperature was $98.4^{\circ} \mathrm{F}$. and the pulse was 90 . An enema brought away a large solid motion, and a considerable amount of loose fæcal matter was evacuated later after further enemata. On the 10 th the temperature was $98.8^{\circ}$ and the pulse was 92 ; the abdominal pain and the sickness continued. At this time the necessity for the consideration of operative interference was pointed out and explained, but this suggestion was not acceded to in spite of the warning that the case was a grave one. The distension increased rapidly, rigidity of the abdominal muscles became evident and great tenderness over the entire right half of the abdomen supervened. Pain immediately before and during micturition followed and continued without abatement until the date of the operation which was ultimately performed. On this day (June 10th) the patient was seen by Sir William Broadbent and the following treat. ment was adopted : a pill of belladonna, morphine, and salol was given every four hours, an ice-bag was placed over the right iliac fossa, and a nutrient enema was administered every four hours. On the same evening the temperature was $98 \cdot 2^{\circ}$ and the pulse was 100 . From this date the vomiting ceased. On the 11th the rigidity and tenderness had extended over the whole abdomen; the pain was incessant and very severe; the temperature rose to $101 \cdot 8^{\circ}$, and the pulse was 120 . Urgent suggestions of surgical aid were still declined. Four leeches were then applied over the right side of the abdomen. Menstruation had commenced during the previous night and it continued during the next three days. The progress of the case continued upon the same lines as before, under the same treatment, and there was increased tenderness with infiltration of the subcutaneous tissues about the right loin and groin. The temperature became persistently higher and the general condition more grave. On the 14 th the patient was seen by Sir William Bennett, who urged immediate operation. Another day's delay was, however, unavoidable and the operation was performed on the afternoon of the 15th with the assistance of Dr. Cahill, the anæsthetic being administered by Dr. F. W. Hewitt. Upon exploring the cæcal region by the usual incision the appendix, which lay posteriorly, intimately matted to the bowel and all the parts around by firm adhesions, was with some diffculty freed and removed. It showed a tight constriction at a quarter of an inch from its junction with the cæcum and another towards its distal end. Between these points it was greatly distended with pus and its wall showed all the conditions of very chronic disease. The extreme distal end was little more than a fibrous cord. No suppuration had occurred outside the appendix itself, but the intestinal coils around were greatly injected and matted by recent adhesions. Upon making the usual further examination of the abdominal cavity a dark firm mass was found occupying the upper part of the pelvis and intimately adherent to the rectum, the uterus, and the bladder. After a considerable extension of the abdominal incision this mas was with very great difficulty separated from the parts with which it was matted and was brought up to the wound. It proved to be an ovarian cyst of about the size of a cocoanut, with a very thick pedicle which had become twisted upon itself for about three-quarters of a complete turn. Its walls were thin and blackish and its contents mainly decomposing blood. The pedicle was ligatured in the usual way and the cyst was removed. The operation, which was necessarily prolonged, was well borne and the subsequent progress was steady and uneventful.

Remarks by Dr. CAHILL.--This case illustrates a difficulty which not unfrequently arises in private practice to prevent the timely treatment of serious internal lesions. The patient's ultimate recovery was undoubtedly very gravely jeopardised by the determined opposition with which the most urgent proposals for surgical treatment were persistently met. It is somewhat remarkable that the severe double operation was so well borne after six days of suffering from acute peritonitis. The situation of the cyst in this case was, I believe, rather unusual in that it was firmly wedged in between the bladder and the uterus, being adherent to the rectum only above the level of the fundus uteri. More recently I have had under my care a case of recurrent pelvic inflammation in which an unsuspected ovarian cyst with torsion of the pedicle was removed by Dr. A. F. Stabb, but in that instance the tumour was firmly impacted in Douglas's pouch, a position which is more frequent.

Remarks by Sir WILLIAM BENNETT. - The association of acute appendicitis with a twisted ovarian pedicle must be a very rare condition, for although cases in which appendicitis has been diagnosed and a twisted ovarian pedicle found upon exploration, the appendix being unaffected, are not altogether rare, I have in the course of a very large experience of abdominal surgery never before met with a case in which operation revealed the two conditions existing at the same time. The question as to which of the two lesions was primary in the present instance is interesting and there seems to be little doubt, judging from the chronic nature of the abscess in the appendix and the extensive localised peritonitis around that structure, that an acute change in the appendix condition led, probably as a consequence of sudden violent intestinal contortions, to a twisting of the ovarian pedicle in consequence of some displacement of the tumour. Considering the difficulty of the operation and the grave condition of the patient the uneventful recovery was not a little remarkable and adds further testimony, if such were needed, to the extraordinary power of resistance possessed by the true friend of the surgeon-the peritoneum.

\section{THE INFLUENCE OF AN EXCESSIVE MEAT DIET ON THE OSSEOUS SYSTEM.}

\section{By D. CHALMEIRS WATSON, M.D. EDIN., F.R.C.P. EDIN,}

I HAVE previously submitted figures to prove that there has been a very great increase in the consumption of animal food in this country in the past 50 years. Whereas in the year 1850 the amount of meat consumed was three pounds per head per annum, in 1900 this had increased to over 50 pounds per head per annum-a very remarkable in crease. It is generally admitted that the excessive use of meat is an important factor in the genesis of many symptoms of disease, more especially of those which are commonly ascribed to a gouty origin. It appears, however, to be a singular fact that in the past 50 years there has been a notable decrease in the incidence of genuine acute gout in 